\title{
Aplicação dos conceitos de proteína bruta e proteína ideal sobre o desempenho de frangos de corte machos e fêmeas criados no inverno ${ }^{1}$
}

\author{
Performance of males and females broilers fed diets based on crude or ideal protein \\ during the winter
}

\author{
Geni Salete de Toledo ${ }^{2}$ Jorge López ${ }^{3}$ Paulo Tabajara Costa ${ }^{4}$ Harvey de Souza $^{5}$
}

\section{RESUMO}

\begin{abstract}
Dois experimentos foram conduzidos com o objetivo de avaliar o desempenho e analisar a viabilidade econômica comparativa entre dois conceitos protéicos e duas linhagens de frangos de corte (Hybro G e Hybro PG), criados no período de inverno, com temperatura média de $16^{\circ} \mathrm{C}$ e UR média de $72 \%$. As aves foram alimentadas com dietas formuladas pelo conceito de Proteína Bruta (PB) sem suplementação de aminoácidos e Proteína Ideal (PI), de 1 a 42 dias de idade nos dois sexos. $O$ delineamento utilizado nos dois experimentos foi inteiramente casualizado num esquema fatorial $2 \times 2$ (2 conceitos protéicos $e$ 2 linhagens) com 6 repetições de 20 aves para cada sexo. Machos não mostraram interação entre proteína $x$ linhagens para as variáveis estudadas; entretanto, machos do conceito PB consumiram mais ração, porém ganharam menos peso $e$ converteram pior que os PI. Para fêmeas, houve interação para a variável conversão alimentar, sendo que as aves do conceito PI da linhagem PG, foram mais eficientes que as aves do conceito PB. Para a mesma categoria, na análise dos efeitos isolados, não houve diferença significativa para consumo, entretanto, as fêmeas PI ganharam mais peso que as fêmeas $P B$. Na análise econômica dos resultados, foi observado que a formulação de dietas PI para ambos os sexos é mais rentável.
\end{abstract}

Palavras-chave: frango de corte, linhagens, proteína bruta, proteína ideal.

\section{ABSTRACT}

Two experiments were conducted to evaluate the performance of broilers and analyze the comparative economical effects of two concepts of protein given to two lines of broilers (Hybro $G$ and Hybro PG) reared during cold weather, average of $16 \mathrm{C}$ and $\mathrm{RH}$ of $72 \%$. The broilers were fed to diets formulated based on the concept of crude protein $(P B)$ with addition of aminoacids or on the ideal protein (PI), from 1 to 42 days of age for both sexes. The experimental design in both experiments was entirely randomized in a factorial $2 \times 2$ (2 protein concept vs 2 lines). The males did not show evidence and the interaction between protein vs lines for all variables studied, however, males receiving crude protein had higher fed consumption, but, had a lower weight gain and worse fed conversion compared to ideal protein, For females there was an interaction for fed conversion, where broilers of the line PG receiving PI were more efficient than those of the concept $P B$. For the same category, analyzing the isolated effects, there was no significant difference for feed consumption, but females of PI were heavier than those of PB. The economical analysis of the results showed that the formulation of the PI concept for both sexes is worth.

Key words: broilers, genetic lines, crude protein, ideal protein.

\section{INTRODUÇÃO}

O crescimento animal é influenciado pelo nível energético e protéico da dieta, sendo que estes são os nutrientes mais onerosos da mesma. Considerando que a produção agro-industrial visa principalmente a eficiente conversão da proteína da dieta em proteína muscular, é conveniente que toda tecnologia seja implementada para viabilizar o menor aporte da parcela protéica das dietas, reduzindo-a, sem influir negativamente no desempenho das aves, ou buscando suplementações que possam melhorar sua eficiência.

Durante anos, as formulações de dietas para aves foram baseadas no conceito de proteína bruta (quantidade de nitrogênio x 6,25). Isso freqüentemente resultou em dietas com um conteúdo de aminoácidos superior ou em desequilíbrio em relação às exigências reais dos animais. O uso de aminoácidos sintéticos objetiva diminuir a excreção de nitrogênio e os custos de produção, em função da redução do nível de proteína bruta das dietas (PENZ, 1996).

\footnotetext{
${ }^{1}$ Parte da tese de doutorado do primeiro autor.

${ }^{2}$ Médico Veterinário, Doutor, Professor Adjunto, Departamento de Zootecnia, Universidade Federal de Santa Maria (UFSM), RS. Autor para correspondência. E-mail: -genit@terra.com.br

${ }^{3}$ Engenheiro Agrônomo, PhD, Professor Titular, Departamento de Zootecnia, Universidade Federal do Rio Grande do Sul.

${ }^{4}$ Médico Veterinário, PhD, Professor Titular, Departamento de Zootecnia, UFSM.

${ }^{5}$ Acadêmico do Curso de Medicina Veterinária, UFSM.
} 
Considerando que a alimentação representa a maior parte dos custos na produção avícola, medidas para reduzir estes custos podem significar maior lucratividade para o setor. Segundo BELLAVER (1994), utilizar matérias primas de composição conhecida, atender as exigências nutricionais, ter programas de alimentação adequados e formular rações de custo mínimo, são medidas que resultam em maior eficiência na produção avícola. O que já é realidade e pode ser afirmado é que os valores de aminoácidos devem ser expressos em termos de aminoácidos digestíveis (AAD) e não mais em aminoácidos totais (AAT); portanto, a exigência não é de proteína e sim de aminoácidos específicos e nitrogênio não específico para a síntese de aminoácidos não essenciais (SUIDA, 2001).

Pesquisas têm demonstrado que as necessidades de aminoácidos das fêmeas são inferiores às dos machos; também sabe-se que o conteúdo protéico da dieta, a relação energia:proteína e os níveis de lisina, metionina e metionina + cistina afetam o desempenho animal e a qualidade de carcaça dos frangos de corte (SUMMERS et al., 1992; BAKER et al., 1996, ZAVIEZO, 1998). Além disso, devemos considerar também que os extremos térmicos se situam nos períodos de verão e inverno, e que existem inúmeros trabalhos que citam diferenças nas exigências nutricionais entre altas e baixas temperaturas.

Levando em consideração estas observações, o presente trabalho teve como objetivos: a) verificar as respostas de desempenho de duas linhagens de frangos de corte, criados com sexos separados no período de inverno, alimentados com dietas formuladas pelo conceito tradicional (PB), que utiliza como base os AAT e pelo critério de proteína ideal (PI), que utiliza como base os AAD; b) fazer uma análise econômica comparativa entre os dois métodos de alimentação.

\section{MATERIAL E MÉTODOS}

Dois experimentos concomitantes foram realizados no Setor de avicultura da UFSM, no período de 11 de julho a 22 de agosto de 2001 com temperatura média de $16{ }^{\circ} \mathrm{C}$. e UR de $72 \%$. Foram utilizados 480 frangos de 1 dia de idade para cada experimento sendo 240 da linhagem Hybro G (A) e 240 da linhagem Hybro PG (B) para o experimento Machos e 240 frangos da linhagem Hybro G e 240 da linhagem Hybro PG para o experimento - Fêmeas. As aves foram alojadas em galpão experimental, distribuídas em 48 boxes com 20 aves cada.
O delineamento experimental para ambos os experimentos, foi inteiramente casualizado em esquema fatorial $2 \times 2$, constituído de dois conceitos protéicos (PB e PI) e duas linhagens (Hybro G e Hybro PG) com 6 repetições de 20 aves cada.

Os pintos foram criados sob condições convencionais de manejo. As dietas utilizadas foram formuladas pelo conceito de PB seguindo as recomendações do NRC (1994), sem suplementação de AA, e pelo conceito de PI (AAD) conforme BAKER \& HAN (1994), obedecendo a um decréscimo para ambos os conceitos de $10 \%$ entre fases criatórias e $5 \%$ entre sexos, seqüencialmente. A energia metabolizável utilizada obedeceu ao mesmo nível para ambos os experimentos, conforme tabela 1.

Foram calculados o peso médio inicial, peso médio final, ganho de peso médio (GP), consumo médio de ração (CR), conversão alimentar (CA), e viabilidade econômica. Para analisar a viabilidade econômica do desempenho, foi utilizado o índice bioeconômico (IEBE) desenvolvido por COSTA (1999). Para o cálculo do custo do ganho de peso vivo por tonelada (R\$/T), multiplicou-se o custo da dieta pela conversão alimentar dentro de cada fase. Para o cálculo total, dividiu-se o somatório das fases pelo ganho e assim se obteve o custo médio da tonelada de ganho de peso vivo.

Os resultados obtidos para ambos os experimentos foram submetidos à análise de variância e as médias comparadas pelo teste $\mathrm{F}$ pelo teste de Tukey. O nível crítico de significância foi de $10 \%$ de probabilidade.

Tabela 1 - Níveis de energia metabolizável, proteína bruta (PB), cálcio (Ca), fósforo disponível (Pd) e aminoácidos utilizados para machos e fêmeas.

\begin{tabular}{lccccccc}
\hline & \multicolumn{1}{c}{$1-21$ dias } & \multicolumn{2}{c}{ 22-35 dias } & & \multicolumn{2}{c}{$36-42$ dias } \\
& PB & PI & PB & PI & & PB & PI \\
\hline Proteína (\%) & 23,00 & 20,97 & 20,70 & 19,61 & 18,63 & 18,08 \\
EM(Kcal/kg) & 3000 & 3000 & 3100 & 3100 & 3200 & 3200 \\
Ca (\%) & 0,90 & 0,90 & 0,86 & 0,86 & 0,82 & 0,82 \\
Pd (\%) & 0,45 & 0,45 & 0,42 & 0,42 & 0,39 & 0,39 \\
Met (\%) & 0,333 & 0,548 & 0,308 & 0,472 & 0,285 & 0,426 \\
Lis (\%) & 1,267 & 1,120 & 1,104 & 1,008 & 0,959 & 0,907 \\
Tre (\%) & 0,907 & 0,750 & 0,815 & 0,705 & 0,731 & 0,656 \\
\hline \multicolumn{7}{c}{ Fêmeas } \\
Proteína (\%) & 21,85 & 19,99 & 19,66 & 18,65 & 17,69 & 17,21 \\
EM(Kcal/kg) & 3000 & 3000 & 3100 & 3100 & 3200 & 3200 \\
Ca (\%) & 0,90 & 0,90 & 0,86 & 0,86 & 0,82 & 0,82 \\
Pd (\%) & 0,45 & 0,45 & 0,42 & 0,42 & 0,39 & 0,39 \\
Met (\%) & 0,321 & 0,518 & 0,297 & 0,456 & 0,275 & 0,402 \\
Lis (\%) & 1,182 & 1,064 & 1,028 & 0,957 & 0,891 & 0,861 \\
Tre (\%) & 0,861 & 0,712 & 0,773 & 0,670 & 0,693 & 0,623 \\
\hline
\end{tabular}

$\mathrm{PB}=$ Proteína bruta; $\mathrm{PI}=$ Proteína ideal , EM= Energia metabolizável .

Ciência Rural, v.34, n.6, nov-dez, 2004. 


\section{RESULTADOS E DISCUSSÃO}

Experimento - machos

Os resultados das médias de desempenho de 1 a 21 e de 1 a 42 dias de idade encontram-se na tabela 2. Não houve interação significativa entre conceito protéico e linhagens para as variáveis estudadas em nenhuma das fases experimentais. Embora numericamente tenha havido maior consumo para as aves do $\mathrm{PB}$, na fase inicial não houve diferença estatística entre os dois conceitos (tabela 2). No período total, as aves alimentadas pelo conceito $\mathrm{PB}$ consumiram mais ração do que as do PI $(\mathrm{P}=0,063)$.

Esses resultados concordam com ROSA et al. (1995), entretanto, são discordantes dos relatados por pesquisas em que aves alimentadas com dietas formuladas por conceito PI tiveram maior consumo de ração do que às do conceito PB (MENDOZA, 1999; LUVISA 2000). A provável explicação para o maior CR das aves do conceito PB, é a de que o consumo também pode ser influenciado pelo teor de proteína da dieta. No caso de uma carência, as aves, em especial, tendem a consumir exageradamente o alimento, como se tentassem assegurar uma ingestão suficiente de aminoácidos. No caso das linhagens, o maior consumo da linhagem B em relação à linhagem A, pode estar associado ao seu maior peso vivo.

Para GP e CA, verificou-se que as aves do conceito PI ganharam mais peso tanto na fase inicial $(\mathrm{P}=0,041)$, como no período total do experimento $(\mathrm{P} \leq$ 0,0001), com conversão alimentar altamente significativa $(\mathrm{P} \leq 0,0001)$ no período total; o mesmo ocorrendo com a linhagem B em relação à linhagem A (Tabela 2). Isso mostra que deve ter ocorrido um melhor balanceamento de energia/aminoácido das dietas PI, pois embora as aves do conceito PB tenham consumido, no período total, mais alimento do que as do PI, ganharam 5,5\% menos peso e com CA 7,2\% pior, provavelmente devido ao gasto de energia para eliminar os catabólitos de nitrogênio (ZAVIEZO 1998; SUIDA, 2001) ou, devido à digestibilidade dos aminoácidos existentes nos ingredientes. Quanto ao desempenho das linhagens, deve haver uma reavaliação dos programas fásicos de alimentação, quando são utilizadas linhagens distintas, pois os dados nos mostram que as exigências nutricionais variam conforme o genótipo do animal.

\section{Experimento - fêmeas}

Os resultados das médias de desempenho de 1 a 21 e de 1 a 42 dias de idade, encontram-se na tabela 3. No período de 1 a 21 dias, para a variável consumo de ração foi observada diferença significativa $(\mathrm{P}=0,0005)$ somente entre linhagens, em que a linhagem $B$ consumiu mais ração que a linhagem A (Tabela 3). Quanto ao GP, verificou-se que houve diferença significativa $(\mathrm{P} \leq 0,0001)$ tanto entre conceitos, como entre linhagens em que as aves alimentadas com dietas formuladas pelo conceito PI e da linhagem $B$, ganharam mais peso do que àquelas alimentadas com dietas formuladas pelo conceito $\mathrm{PB}$ e linhagem A. Entretanto, somente houve interação significativa $(\mathrm{P}=0,034)$ entre conceitos e linhagens, para a variável CA; onde para o conceito PI não houve

Tabela 2 - Consumo de ração (CR), ganho de peso (GP), e conversão alimentar (CA) de frangos de corte, machos, no período de 1-21 e de 1-42 dias de idade segundo o conceito protéico e a linhagem

\begin{tabular}{|c|c|c|c|c|c|c|}
\hline & \multicolumn{3}{|c|}{1 a 21 dias } & \multicolumn{3}{|c|}{1 a 42 dias } \\
\hline & CR(g) & GP(g) & CA & CR(g) & GP(g) & CA \\
\hline \multicolumn{7}{|c|}{ Conceito protéico (CP) } \\
\hline Proteína bruta & 1241 & $721 \mathrm{~b}$ & 1,726 & 4698a & $2408 b$ & $1,942 b$ \\
\hline Proteína ideal & 1237 & $744 a$ & 1,663 & $4602 b$ & $2541 \mathrm{a}$ & $1,811 \mathrm{a}$ \\
\hline \multicolumn{7}{|c|}{ Linhagem*(L) } \\
\hline$\overline{\mathrm{A}}$ & $1220 b$ & $705 b$ & $1,733 b$ & $4492 b$ & 2344b & $1,911 b$ \\
\hline B & $1258 a$ & $760 \mathrm{a}$ & $1,656 a$ & $4806 a$ & $2606 a$ & $1,842 \mathrm{a}$ \\
\hline \multicolumn{7}{|c|}{ Probabilidade } \\
\hline Conceito protéico & 0,798 & 0,041 & 0,118 & 0,063 & 0,0001 & 0,0001 \\
\hline Linhagem & 0,030 & 0,0001 & 0,059 & 0,0001 & 0,0001 & 0,003 \\
\hline Interação CP x L & 0,233 & 0,508 & 0,234 & 0,285 & 0,661 & 0,507 \\
\hline$\overline{\mathrm{CV} \%}$ & 3,20 & 3,62 & 5,60 & 2,54 & 1,81 & 2,68 \\
\hline
\end{tabular}

a, $\mathrm{b}=$ =médias seguidas de letras diferentes nas colunas, diferem entre si pelo teste $\mathrm{F}$

* A= Hybro G; B= Hybro PG 
Tabela 3 - Consumo de ração (CR), ganho de peso (GP), e conversão alimentar (CA) de frangos de corte, fêmeas, no período de 1-21 e de 1 a 42 dias de idade segundo o conceito protéico e a linhagem

\begin{tabular}{|c|c|c|c|c|c|c|}
\hline & \multicolumn{3}{|c|}{1 a 21 dias } & \multicolumn{3}{|c|}{1 a 42 dias } \\
\hline & CR(g) & GP(g) & CA & CR(g) & GP(g) & CA \\
\hline \multicolumn{7}{|c|}{ Conceito protéico (CP) } \\
\hline Proteína bruta & 1172,8 & $655,0 \mathrm{~b}$ & 1,774 & 4205 & 2027b & 2,049 \\
\hline Proteína ideal & 1171,9 & 695,3a & 1,686 & 4232 & $2144 a$ & 1,953 \\
\hline \multicolumn{7}{|c|}{ Linhagem* (L) } \\
\hline A & $1142,8 b$ & $647,9 b$ & 1,779 & 4051b & 1983b & 2,030 \\
\hline $\mathrm{B}$ & $1201,8 \mathrm{a}$ & $702,3 a$ & 1,681 & $4387 a$ & 2189a & 1,972 \\
\hline \multicolumn{7}{|c|}{ Interação } \\
\hline Proteína bruta A & 1154,5 & 631,0 & $1,856 b$ & 4021 & 1915 & $2,095 a$ \\
\hline Proteína bruta B & 1191,1 & 679,0 & $1,692 \mathrm{a}$ & 4390 & 2142 & $2,003 b$ \\
\hline Proteína ideal A & 1131,2 & 664,9 & $1,702 \mathrm{a}$ & 4080 & 2052 & $1,964 \mathrm{bc}$ \\
\hline Proteína ideal B & 1212,6 & 725,7 & $1,671 \mathrm{a}$ & 4384 & 2237 & $1,941 \mathrm{c}$ \\
\hline \multicolumn{7}{|c|}{ Probabilidade } \\
\hline Conceito protéico & 0,949 & 0,0001 & 0,007 & 0,530 & 0,0001 & 0,0001 \\
\hline Linhagem & 0,0005 & 0,0001 & 0,003 & 0,0001 & 0,0001 & 0,0003 \\
\hline Interação CP x L & 0,132 & 0,452 & 0,034 & 0,455 & 0,369 & 0,017 \\
\hline CV\% & 2,97 & 3,02 & 4,14 & 2,47 & 2,69 & 1,61 \\
\hline
\end{tabular}

a, b = médias seguidas de letras diferentes nas colunas diferem entre si pelo teste de Tukey.

*A=Hybro G; B= Hybro PG.

diferença de conversão entre as linhagens, havendo, porém, para o conceito $\mathrm{PB}$ em que a linhagem A obteve pior CA que a linhagem $\mathrm{B}$, diferindo também das linhagens A e B do PI.

No período total, para CR observou-se diferença significativa somente entre as linhagens, em que a linhagem $B$, consumiu mais ração que a linhagem A $(P \leq 0,0001)$, havendo consumo similar entre os conceitos. Estes resultados concordam com ROSA et al. (1995) e PENA et al. (1996), que também não observaram diferença significativa para CR entre dietas formuladas por AAD e AAT. Quanto ao GP, embora sem diferença significativa na fase final entre conceitos, houve maior ganho para as aves do PI. No entanto, entre as linhagens, houve diferença altamente significativa $(\mathrm{P}=0,003)$ com a linhagem $\mathrm{B}$ ganhando mais peso do que a linhagem $\mathrm{A}$.

Para a variável CA, verificou-se que no período total, houve interação entre conceito e linhagens $(\mathrm{P}=0,017)$, sendo que para o conceito $\mathrm{PB}$, não foi verificada diferença entre as duas linhagens, o mesmo ocorrendo com o conceito PI; porém, houve diferença entre a linhagem A do PB, que obteve pior índice de conversão do que a linhagem A do conceito PI.

Os resultados obtidos no período total do experimento para o índice de eficiência bio-econômica (IEBE), encontram-se na tabela 4. Para os machos, o custo médio alimentar para uma $\mathrm{T}$ de ganho de peso vivo, foi 4,97\% menos dispendioso para o conceito PI do que para o PB.

O custo médio ponderado das três dietas fásicas utilizadas no presente experimento foi para machos de R\$320,3 e 326,6 para PB e PI respectivamente. Portanto as dietas formuladas pelo conceito PB foram cerca de 1,93\% menos dispendiosas, mas proporcionaram um custo de produção 4,40\% maior por $\mathrm{T}$ de ganho de peso vivo do que o PI.

Para fêmeas, o custo médio ponderado das três dietas fásicas utilizadas no presente experimento,

Tabela 4 - Custo para produzir 1 ton de ganho de peso vivo (R\$/ton/GP) para machos e fêmeas (inverno)

\begin{tabular}{|c|c|c|c|}
\hline & $\mathrm{CA}^{*}$ & $\mathrm{R} \$ /$ ton/R** & $\mathrm{R} \$ / \mathrm{Ton} / \mathrm{GP}^{* * *}$ \\
\hline \multicolumn{4}{|c|}{ MACHOS } \\
\hline Proteína bruta & 1,964 & 320,3 & 629,0 \\
\hline Proteína ideal & 1,841 & 326,6 & 601,3 \\
\hline Diferença (\%) & & 1,93 & 4,40 \\
\hline \multicolumn{4}{|c|}{ FÊMEAS } \\
\hline Proteína bruta & 2,088 & 305,7 & 638,3 \\
\hline Proteína ideal & 1,982 & 312,5 & 619,4 \\
\hline Diferença (\%) & & 2,20 & 2,96 \\
\hline
\end{tabular}

*CA= conversão alimentar

$* * \mathrm{R} \$ /$ ton $/ \mathrm{R}=$ reais por tonelada de raçao

$* * * \mathrm{R} \$ /$ ton/GP= reais por tonelada de ganho de peso

Ciência Rural, v.34, n.6, nov-dez, 2004. 
foi de R\$ 305,7 e 312,5 para PB e PI respectivamente. Portanto as dietas formuladas pelo conceito PB foram cerca de 2,20\% menos dispendiosas e proporcionaram um custo de produção para uma T de GPV de 2,96\% mais dispendioso; o que concorda com os resultados obtidos por ALBINO (1991); MENDOZA (1999) e LUVISA (2000) que também observaram que rações formuladas com base em AAD proporcionaram maior lucro.

\section{CONCLUSÕES}

Dietas à base de milho e farelo de soja, formuladas para atender às exigências de aminoácidos digestíveis, ou seja, pelo conceito de proteína ideal, proporcionam melhor desempenho biológico em relação àquelas formuladas pelo conceito de proteína bruta. As dietas formuladas por proteína ideal mesmo custando mais por unidade protéica, devido à agregação de AA sintéticos, promovem melhor eficiência produtiva, proporcionando maiores retornos econômicos, comparadas às dietas formuladas com alto nível de PB e não suplementadas em aminoácidos sintéticos.

\section{REFERÊNCIAS BIBLIOGRÁFICAS}

ALBINO, L.F.T. Sistemas de avaliação nutricional de alimentos e suas aplicações, na formulação de rações para frangos de corte. 1991. 141f. Tese (Doutorado) - Programa de Pós-graduação em Zootecnia, Departamento de Zootecnia, Universidade Federal de Viçosa.

BAKER, D.H.; HAN, Y. Ideal aminoacid profile for chicks during the first weeks posthatching. Poultry Science, Champaign, v.73, p.1441-1447, 1994.

BAKER,D.H. et al. Sulfur aminoacid requirement and cystine replacement value of broiler chicks during the period three to six weeks posthatching. Poultry Science, Champaign, v.75, n.6, p.737-742, 1996.

BELLAVER, C. Metodologias para a determinação do valor das proteínas e utilização de valores disponíveis nas dietas de nãoruminantes. In: REUNIÃO ANUAL DA SOCIEDADE BRASILEIRA DE ZOOTECNIA, 31., 1994, Maringá. Simpósio internacional de produção de não-ruminantes. Anais... Maringá : EDUEM, 1994. p.1-23.

COSTA, P.T.C. Avaliação econômica do frango de corte na fase final. In: CONFERENCIA APINCO DE CIÊNCIA E TECNOLOGIA AVÍCOLAS 1999, Campinas. Anais... Campinas: FACTA, 1999. p.71-82.

LUVISA, L. Desempenho de frangos de corte sexados, alimentados pelos conceitos protéicos convencional versus ideal. 2000. 90f. Dissertação (Mestrado em Produção Animal) - Curso de Pós-graduação em Zootecnia, Universidade Federal de Santa Maria.

MENDOZA, M.O.B. Desempenho de frangos de corte, sexados, submetidos a dietas formuladas pelos conceitos de Proteína Bruta versus Proteína Ideal. 1999. 73f. Dissertação (Mestrado em Produção Animal) - Curso de Pós-graduação em Zootecnia, Universidade Federal de Santa Maria.

NRC. Nutrient requirements of poultry. 9.ed. Washington : National Academy, 1994. 155p.

PENA, L.D. et al. Evaluación del ciclo productivo de pollos de engorda, alimentados com dietas elaboradas a base de aminoacidos totales y digestibles (mediante el concepto de proteina ideal). In:REUNION NACIONAL DE INVESTIGACION PECUARIA, 1996, Cuernavaca. Resumos... Cuernavaca, [s.n.], 1996. p.299.

PENZ JR. A.M. O conceito de proteína ideal para monogástricos. In: CONGRESSO NACIONAL DE ZOOTECNIA, 1996, Porto Alegre. Anais... Porto Alegre, [s.n.], 1996. p.71-84.

ROSA, P.S. et al. Comparação de dietas práticas para frangos formuladas para atender diferentes exigências de aminoácidos. In: CONFERÊNCIA APINCO DE CIÊNCIA E TECNOLOGIA AVÍCOLAS 1995, Curitiba. Anais... Curitiba : FACTA, 1995. p.63-64.

SUIDA, D. Formulação por proteína ideal e conseqüências técnicas, econômicas e ambientais. In: SIMPÓSIO INTERNACIONAL DE NUTRIÇÃO ANIMAL: PROTEÍNA IDEAL, ENERGIA LIQUIDA E MODELAGEM, 2001, Santa Maria. Anais... Santa Maria : EMBRAPA, 2001. p.27-43.

SUMMERS, J.D.; SPRATT, D.; ATKINSON, J.L. Broiler weight gain and carcass composition when fed diets varying in amino acid balance, dietary energy, and protein level. Poultry Science, Champaign, v.71, p.263-273, 1992.

ZAVIEZO, D. Proteína ideal - Novo conceito nutricional da formulação de rações para aves e suínos. Avicultura industrialSão Paulo, n.10, p.16-20, 1998. 